\title{
Uncorrected refractive errors, presbyopia and spectacle coverage in Kamuli District, Uganda
}

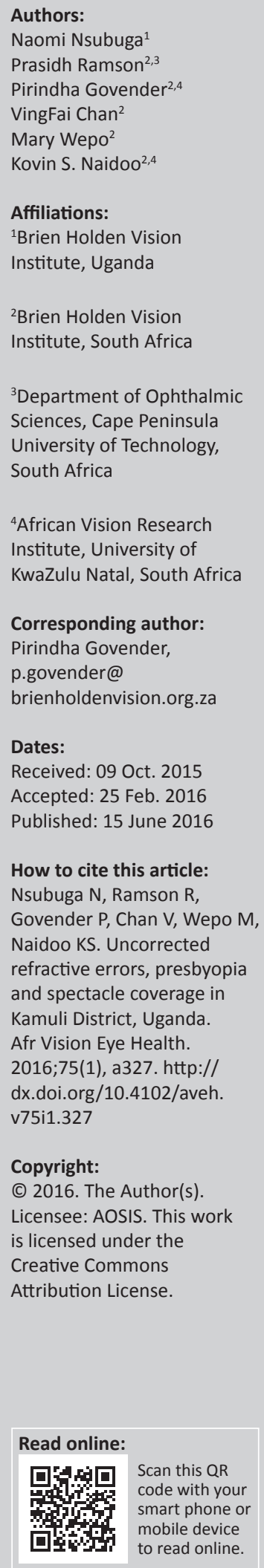

Background: Successful refractive error programmes arise from evidence that can be collected cost effectively and timely.

Aim: To investigate the prevalence of uncorrected refractive error (URE), presbyopia and spectacle coverage in the Kamuli district, Uganda.

Setting: The study was conducted in the Kamuli district in Uganda.

Methods: The Rapid Assessment of Refractive Error (RARE) study design is a communitybased cross-sectional study using multistage cluster random sampling to gather information on refractive errors and presbyopia. Subjects aged 15 years and older were selected from the population in Kamuli district in Uganda. Vision impairment due to URE at distance and near and barriers to uptake of refractive error services were investigated.

Results: Participants, $N=3281$ (57.6\% male), with an age range of $15-92$ years were enumerated and the response rate was $100 \%$. The prevalence of refractive errors was $4.6 \%$ (95\% confidence interval [CI]: $3.7-5.5)$ and the spectacle coverage was $5.96 \%(95 \%$ CI $1.74 \%-10.18 \%)$. The prevalence of uncorrected presbyopia was 50.3\% (95\% CI $47.6 \%-53.0 \%)$ and the spectacle coverage was $0 \%$. Thirty-three (or 1\%) respondents were current spectacle users. One-hundred fourteen people (3.5\%) had previously used spectacles; however, $50.9 \%$ of them discontinued spectacle use a year before the study because the spectacles were broken or scratched. The major barriers to spectacle uptake were accessibility of services and affordability of spectacles.

Conclusion: The prevalence of URE and the barriers to uptake of refractive services will inform the implementation of refractive services in the study area.

\section{Introduction}

Globally, distance refractive error has been cited as the primary $(53 \%)$ cause of moderate and severe vision impairment (that is, visual acuity in the better eye $<6 / 18$ but great than $6 / 120$ ). ${ }^{1}$ While still being one of the more easily diagnosed, investigated, and managed conditions, there are still an estimated 670 million people worldwide who do not have spectacles, 517 million without near correction and 153 million without distance correction. ${ }^{2,3}$ If left uncorrected, refractive error has the potential to cause significant social and economic implications. ${ }^{4}$ This, therefore, emphasises the need for effective strategies to reach those in need of refractive correction.

Effective and efficient models of eye care delivery can best be developed when informed by contextual epidemiological data. ${ }^{5}$ Traditionally, prevalence is gathered from large-scale population-based epidemiological studies, which are, however, expensive and time-consuming to conduct. ${ }^{6}$ Rapid Assessment Studies ${ }^{6,7,8,9}$ provide an alternative way of eliciting required population-based data with limited resources and time spent. They involve an assessment of vision impairment due to uncorrected refractive error (URE), presbyopia, and spectacle coverage and barriers to uptake of refractive services. This data can be collected at base-line levels; however, given their expedited nature, these studies can be repeated periodically. Therefore, the programmes can be monitored, their impact can be measured, and modifications can be implemented in response to the needs of the population.

As one of the many African countries in a state of post-conflict recovery, Uganda is trying to rebuild the environment so that equitable and comprehensive health care can be provided. ${ }^{10}$ Some parts of the country still remain in a state of political instability. ${ }^{11}$ The distribution of services, appropriate skills, productivity, quality of services, and the retention of healthcare workers are among many factors that can affect the health workforce, especially in a post-conflict environment. ${ }^{10}$ The planning, management, and implementation of comprehensive health services will be informed by evidence of needs. In Uganda, there have been some fragmented efforts in 
determining the eye health needs of the population., ${ }^{9,12}$ Considering the resource constraints of the country, a Rapid Assessment of Refractive Error (RARE) study was undertaken to inform cost-effective solutions for refractive service delivery. The specific objectives of the study were to determine the prevalence of URE at distance and near in persons 15 years and older, assess spectacle coverage, and identify the barriers to uptake of services among the investigated persons.

\section{Research methods and design Study design}

A RARE study design was used in the current study. It is a validated design that has been adopted by numerous other studies. ${ }^{7,8,13}$

\section{Study area}

A community-based cross-sectional study was conducted in the Kamuli district located in the eastern region of Uganda. The demographic profile of the study area closely resembled the larger Ugandan population. The last census conducted in 2002 revealed a district population of $707332 .{ }^{14}$ The gender distribution was almost comparable, with more females than males. More than half of the population (53\%) was under the age of 15 years.

The health care needs of the district are served by two hospitals, one government and one non-government organisation (NGO) funded; two quaternary government health centres; ten tertiary government health centres; and 35 secondary health centres, 18 government and 17 NGO. The eye health workforce in the district comprised of two ophthalmic clinical officers (OCOs) who were based at the Kamuli District Hospital. Referrals were sent from this centre to the Jinja Regional Referral Hospital located $68 \mathrm{~km}$ south of Kamuli town. There were two consultant ophthalmologists and several OCOs based in this regional hospital.

\section{Sampling}

Probability Proportional to Size (PPS) sampling using the Uganda census data of 2002 was conducted to generate a list of 60 random clusters of subjects aged 15 years and older within the study area. The 60 clusters chosen fell within the time frame and budget allocations for the study and 55 people were selected by random walk in each cluster. The sample size was calculated using the equation: $\mathrm{S}_{\text {infinite population }}=$ $[\mathrm{Z} * \mathrm{Z}(\mathrm{P}(1-\mathrm{P})) / \mathrm{D} * \mathrm{D}]$, where $\mathrm{S}$ is the sample size for simple random sampling, $[\mathrm{P}$, the expected prevalence of the condition (7\%), D is half the width of the desired sample confidence interval (0.2), $\mathrm{Z}$ is the percentile of the standard normal distribution, determined by the specified confidence level (1.96 for 95\% CI). Multiplying S $\times$ design effect (DEFF) provided the resultant sample size of 3281 which was based on a predicted non-response rate of $10 \% .{ }^{15}$ The sample calculation was automatically computed by the RAAB software package (Available at http:/ / www.cehjournal.org/ resources/raab/).

\section{Study definitions}

For the purposes of this study, the following definitions were employed:

- 'Residing in the household' was clearly defined for each survey area as 'living in the same dwelling for at least 6 months in a year.'

- Visual impairment was defined as binocular presenting visual acuity worse than 6/12.

- URE was defined as presenting visual acuity worse than $6 / 12$ but improving to at least $6 / 12$ or better with a pinhole.

- Presbyopia was defined as binocular near vision less than N8 (or 6/12) at the subject's habitual working distance in individuals greater than 35 years and who had binocular distance visual acuity of $6 / 12$ or better.

- Spectacle coverage was calculated by the equation: [met need/(met need + unmet need)] $\times 100 \%$; where 'met need' was defined as the number of subjects with spectacles having binocular unaided VA less than 6/12, but improving to or better than $6 / 12$; 'unmet need' was defined as the number of subjects with binocular VA less than $6 / 12$, but improving to $6 / 12$ or better with refractive correction.

\section{Data collection}

Enumeration and clinical examination of eligible subjects was conducted by three teams, each comprising of one OCO and three enumerators. To ensure standardisation of enumeration and clinical procedures, fieldwork was preceded by 2 days of training. The training sessions involved detailed instructions on study procedures and protocols. InterObserver Variability (IOV) testing was conducted during the training to determine the level of agreement (kappa value) between clinicians. An acceptable kappa value of 0.8 was achieved, indicating that there was adequate agreement among clinicians.

The standardised RARE study design was followed to determine the individuals' eligibility for inclusion in the study and for clinical data collection. ${ }^{6}$ All persons with distance VA less than 6/12 in their better eye and near VA less than $6 / 12$ were referred to the nearest facility providing eye care services for a comprehensive eye examination and prescription of spectacles. Those individuals with URE were interviewed to determine the barriers to accessing refractive services.

\section{Data analysis}

A two-step analysis of data was conducted using crude proportions and logistic regressions. Frequency distributions were used to present demographic and prevalence data, while categorical data were analysed using the Fisher's exact and chi-square tests. Age is presented as a median with its interquartile range (IQR) due to it not having a normal distribution. Logistic regressions were applied to ascertain the strength of association between URE and variables of interest. 


\section{Ethical considerations}

The study adhered to the tenets of the Declaration of Helsinki governing research involving human subjects. Ethical approval was obtained from the University of KwaZulu Natal's Biomedical Research Ethics Committee (BREC).

\section{Results}

Only one from the total sample of 3281 subjects enumerated was not examined (which resulted in a response rate of almost $100 \%$ ). Males formed $57.6 \%$ of the sample. The median age of the sample was 42 years (IQR 30 - 55 years). In all age groups, there were more males than females.

Thirty-five percent of respondents did not complete primary school and $20.9 \%$ of respondents had no formal schooling (Table 1). Table 1 provides a summary of the demographic profile of the sample. Almost half of the respondents (47.6\%) were engaged in home duties, while $27.5 \%$ were involved in agricultural work.

\section{Visual status of the sample}

The majority of the sample (89.6\%) presented with normal distance vision according to the study definitions (Table 2). Table 2 provides a visual profile of the sample including vision without any correction (uncorrected vision); vision with the participants' habitual prescription (presenting vision); and corrected vision, which is vision with pinhole.
One hundred and twenty-six participants (3.8\%, 95\% CI: 3.24 - 4.56) presented with mild vision impairment while 153 participants $(4.6 \%$; 95\% CI: 4.00 - 5.44) presented with moderate to severe vision impairment and $1.6 \%$ (95\% CI: $1.24-2.11$ ) were binocularly blind.

\section{Uncorrected refractive error}

The prevalence of URE was $4.6 \%$ (95\% CI: $3.7-5.5)$. There appeared to be no statistically significant association between URE and gender (Fisher's exact; $p=0.614$ ). The differences in the proportion of subjects with URE were found to be statistically significant between the age groups $\left(X_{9}^{2}=124.171, p<0.000\right)$, with URE being most prevalent $(53.0 \%)$ among individuals 60 years and older. Multiple logistic regression (Table 3) showed that participants 60 years and older were 25.2 times (95\% CI $6.6-96.1)$ more likely to have URE $(p=0.000)$. Statistically significant associations were also found between education and URE, (Fisher's exact; $p<0.000$ ), with a greater percentage of participants $(75.5 \%)$, who did not attend school or did not complete primary school having URE. The association between occupation and URE was statistically significant $\left(X_{10}^{2}=24.425, p=0.007\right)$ with the majority of respondents with URE engaged in home duties $(60.9 \%)$ and $24.5 \%$ of respondents engaged in agricultural activities. Based on the study definitions, the spectacle coverage for refractive error was estimated at $5.96 \%$ (95\% CI $1.74 \%-10.18 \%)$.

TABLE 1: Age, gender and educational level composition of subjects in the survey area.

\begin{tabular}{|c|c|c|c|c|c|}
\hline \multirow[t]{2}{*}{ Criteria } & \multirow[t]{2}{*}{ Variant } & \multicolumn{2}{|c|}{ Male } & \multicolumn{2}{|c|}{ Female } \\
\hline & & $n$ & $\%$ & $n$ & $\%$ \\
\hline \multirow[t]{10}{*}{ Age group (years) } & $15-19$ & 156 & 8.3 & 108 & 7.8 \\
\hline & $20-24$ & 168 & 8.9 & 99 & 7.1 \\
\hline & $25-29$ & 166 & 8.8 & 110 & 7.9 \\
\hline & $30-34$ & 141 & 7.5 & 132 & 9.5 \\
\hline & $35-39$ & 171 & 9.1 & 142 & 10.2 \\
\hline & $40-44$ & 179 & 9.5 & 162 & 11.7 \\
\hline & $45-49$ & 218 & 11.5 & 170 & 12.2 \\
\hline & $50-54$ & 182 & 9.6 & 121 & 8.7 \\
\hline & $55-59$ & 124 & 6.6 & 73 & 5.6 \\
\hline & $>60$ & 384 & 20.3 & 274 & 19.7 \\
\hline \multirow[t]{5}{*}{ Education level } & No formal schooling & 216 & 11.4 & 468 & 33.6 \\
\hline & Did not complete primary school & 688 & 36.4 & 459 & 33 \\
\hline & Primary school completed & 398 & 21.1 & 207 & 14.9 \\
\hline & Did not complete secondary school & 370 & 19.6 & 180 & 12.9 \\
\hline & Secondary school completed & 216 & 11.4 & 77 & 5.5 \\
\hline
\end{tabular}

Male: $n=1889 ; 57.6 \%$; Female: $n=1391 ; 42.4 \%$.

TABLE 2: Visual profile of the sample.

\begin{tabular}{|c|c|c|c|c|c|c|c|}
\hline \multirow[t]{2}{*}{ Visual acuity classification } & \multirow[t]{2}{*}{ Visual acuity } & \multicolumn{2}{|c|}{ Uncorrected vision } & \multicolumn{2}{|c|}{$\begin{array}{l}\text { Presenting vision (vision with } \\
\text { spectacles, if any) }\end{array}$} & \multicolumn{2}{|c|}{ Corrected vision (vision with pinhole) } \\
\hline & & $n$ & $\%$ & $N$ & $\%$ & $n$ & $\%$ \\
\hline Normal vision & $\geq 6 / 12$ & 2791 & 85.1 & 2941 & 89.6 & 2942 & 89.7 \\
\hline Mild Vision Impairment & $<6 / 12$ to $\geq 6 / 18$ & 195 & 5.9 & 126 & 3.8 & 126 & 3.8 \\
\hline Moderate Visual Impairment & $<6 / 18$ to $\geq 6 / 60$ & 180 & 5.5 & 116 & 3.5 & 116 & 3.5 \\
\hline Severely Visual Impairment & $<6 / 60$ to $\geq 1 / 60$ & 53 & 1.6 & 37 & 1.1 & 37 & 1.1 \\
\hline Blind & $<1 / 60$ & 55 & 1.7 & 53 & 1.6 & 53 & 1.6 \\
\hline Missing & - & 6 & 0.2 & 7 & 0.2 & 6 & 0.2 \\
\hline Total & - & 3280 & 100 & 3280 & 100 & 3280 & 100 \\
\hline
\end{tabular}




\section{Uncorrected presbyopia}

Two-thousand two-hundred people (2200 or $67.1 \%$ ) in the sample were above 35 years of age. The prevalence of uncorrected presbyopia in this sample was 50.3\% (95\% CI $47.6 \%-53.0 \%)$. A larger percentage of males $(53.6 \%, 95 \% \mathrm{CI}$ $50.0 \%-57.1 \%$ ) presented with presbyopia compared to females $(45.9 \%$, 95\% CI 41.8\% - 49.9\%). Statistically significant correlations $(p=0.000)$ were found between uncorrected presbyopia and gender, education, and occupational status. Of those participants with uncorrected presbyopia, 60.9\% were male, $19.3 \%$ did not complete primary school, and $49.3 \%$ were involved in home duties. Multiple logistic regression showed that people who were in the age group 55 - 59 years were most likely ( 8.7 times; $95 \%$ CI $5.2-14.5)$ to have uncorrected presbyopia $(p=000)$ compared to the younger participants. Spectacle coverage for presbyopia was zero percent. However, $86(7.8 \%)$ of the participants with presbyopia wore spectacles previously. The associations between demographics and presbyopia spectacle coverage were beyond the scope of the study.

\section{Spectacle wear}

Only $33(1.0 \%)$ participants in the sample were wearing spectacles at the time of the study, while 114 participants $(3.5 \%)$ reported having previously worn spectacles. The majority of participants who used spectacles previously or were using spectacles at the time of the study were using them for reading $(76.7 \%)$ or distance viewing $(18.5 \%)$ and only $4.8 \%$ of spectacle users wore either bifocals or multifocal spectacles.

Among the 114 participants (3.5\%) who had previously worn spectacles, the majority (50.9\%) had discontinued wear a year before the study or between one and two years prior (29.8\%). Among the reasons for discontinuing spectacle use were broken or scratched $(65.8 \%)$, lost $(17.5 \%)$, or uncomfortable to wear $(11.4 \%)$.

\section{Barriers to uptake of eye care (refractive) services}

One objective of the study was to identify reasons why people with vision loss due to refractive error or presbyopia, did not wear spectacles despite refractive services being provided. Among the barriers reported was affordability of the spectacles $(76 \%)$, inaccessibility of services $(53 \%)$, and affordability of the eye examination (51\%) (Figure 1).

\section{Discussion}

The study area is one of the poorest districts in Uganda with $80 \%$ of the population living in rural areas ${ }^{16}$ and, therefore, research in this area could inform policy and decision makers. The current study to assess UREs, presbyopia, and

TABLE 3: Odds ratios of age, sex, education and occupation with refractive error and presbyopia.

\begin{tabular}{|c|c|c|c|c|c|}
\hline \multirow[t]{2}{*}{ Criteria } & \multirow[t]{2}{*}{ Variant } & \multicolumn{2}{|c|}{ Refractive error } & \multicolumn{2}{|c|}{ Presbyopia } \\
\hline & & OR & $95 \% \mathrm{Cl}$ & OR & $95 \% \mathrm{Cl}$ \\
\hline \multirow[t]{10}{*}{ Age in years } & $15-19$ & 1 & - & Not applicable & - \\
\hline & $20-24$ & 1.14 & $0.17-7.49$ & Not applicable & - \\
\hline & $25-29$ & 1.4 & $0.23-8.44$ & Not applicable & - \\
\hline & $30-34$ & 2.91 & $0.64-13.17$ & Not applicable & - \\
\hline & $35-39$ & 4.43 & $1.10-17.78$ & Not applicable & - \\
\hline & $40-44$ & 4.58 & $1.15-18.30$ & 3.46 & $2.30-5.22 *$ \\
\hline & $45-49$ & 10.82 & $2.96-39.55^{*}$ & 6.59 & 4.48-9.69* \\
\hline & $50-54$ & 9.83 & $2.45-39.48 *$ & 6.81 & 4.68-9.91* \\
\hline & $55-59$ & 9.82 & $2.06-46.73 *$ & 8.72 & $5.24-14.50 *$ \\
\hline & $60+$ & 25.2 & $6.61-96.06 *$ & 3.49 & $2.36-5.16^{*}$ \\
\hline \multirow[t]{2}{*}{ Sex } & Male & 1 & - & 1 & - \\
\hline & Female & 1.02 & $0.76-1.36$ & 1.12 & $0.85-1.46$ \\
\hline \multirow[t]{6}{*}{ Education } & No Formal Schooling & 1 & - & 1 & - \\
\hline & Primary School Incomplete & 1.23 & $0.84-1.80$ & 2.4 & $1.82-3.17^{*}$ \\
\hline & Primary School Complete & 0.71 & $0.36-1.42$ & 3.14 & $2.16-4.56^{*}$ \\
\hline & Secondary School Incomplete & 0.54 & $0.26-1.13$ & 4.49 & $3.07-6.56^{*}$ \\
\hline & Secondary School Complete & 1.25 & $0.52-3.00$ & 3.82 & $2.34-6.25^{*}$ \\
\hline & Don't Know & - & Empty & - & Empty \\
\hline \multirow[t]{11}{*}{ Occupation } & Professional & 1 & - & 1 & - \\
\hline & Teacher & 0.62 & $0.05-7.69$ & 2.17 & $1.07-4.39$ \\
\hline & Shop keeper & 1.71 & $0.11-25.84$ & 2.72 & $0.77-9.61$ \\
\hline & Clerical job & 2.93 & $0.22-39.61$ & 4.3 & $0.86-21.62$ \\
\hline & Construction work & 1.41 & $0.09-22.12$ & 1.66 & $0.54-5.07$ \\
\hline & Farm/agriculture & 1.66 & $0.23-11.87$ & 1.37 & $0.62-3.00$ \\
\hline & Home duties & 2.22 & $0.32-15.46$ & 1.73 & $0.73-4.09$ \\
\hline & Armed services & 3.03 & $0.53-17.36$ & 2.11 & $0.70-6.34$ \\
\hline & Student/Trainee & 8.22 & $0.79-85.54$ & - & Empty \\
\hline & Not working & 1.51 & $0.18-12.89$ & 0.76 & $0.24-2.42$ \\
\hline & Others & 0.49 & $0.04-5.34$ & 2.46 & $1.00-6.03$ \\
\hline
\end{tabular}

$\mathrm{OR}$, odds ratio; $\mathrm{Cl}$, confidence interval.

$*$, indicates significant associations. 


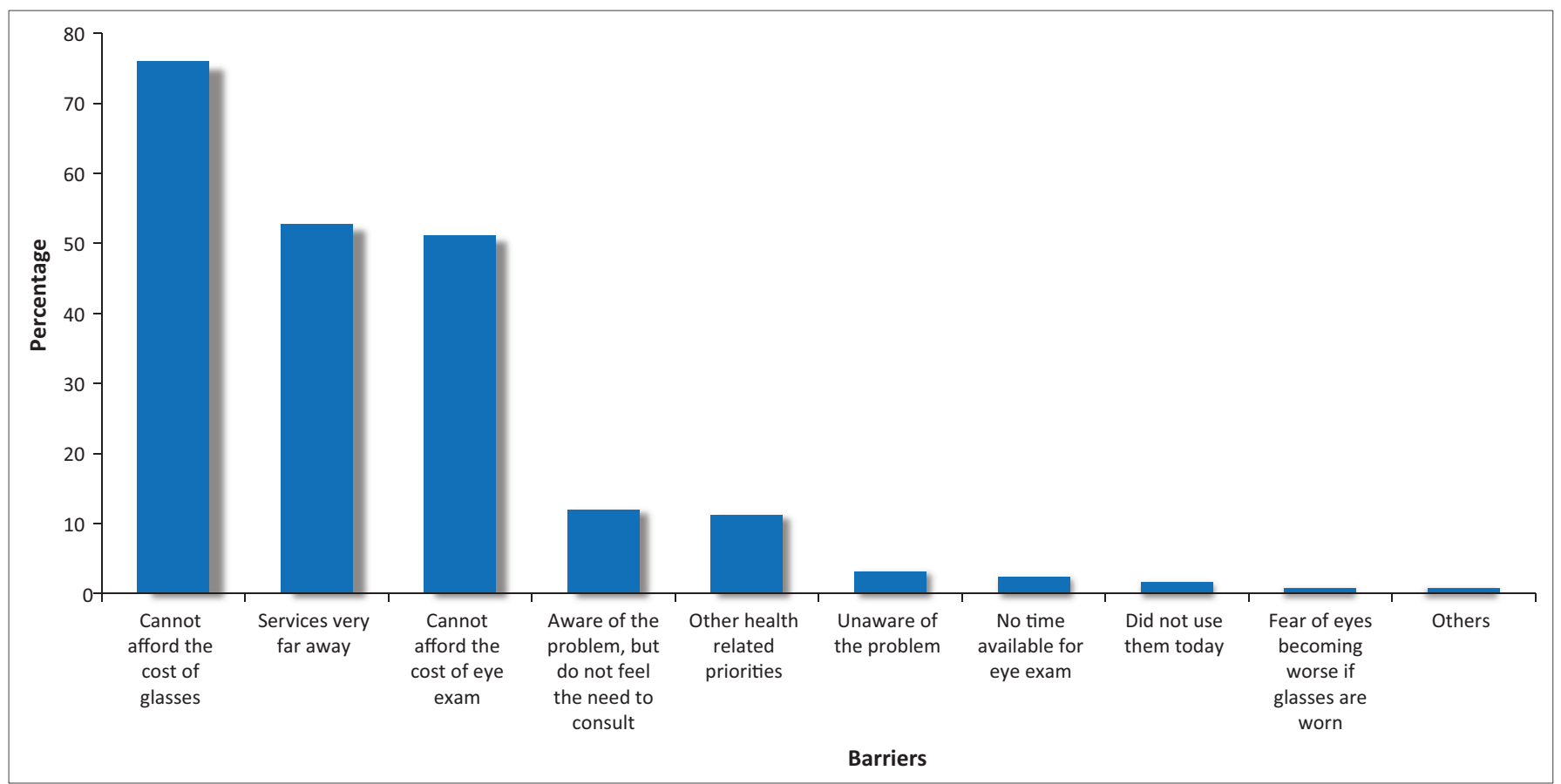

FIGURE 1: Barriers to uptake of refractive services.

spectacle coverage in the Kamuli district in Uganda was conducted to provide evidence on the effectiveness of current refractive services in order to identify the gaps in the provision of refractive services in the study area and the country.

The prevalence of URE in Uganda (4.6\%; 95\% CI: 3.7\% - 5.5\%) was lower than the prevalence found in RARE studies conducted in Eritrea (6.4\%; 95\% CI: 5.6\% - 7.2\%) ${ }^{13}$ and Tanzania $(7.5 \%$; 95\% CI: $6.65 \%-8.54 \%) .{ }^{8}$ However, though the prevalence was lower, the shortage of refractive services means a scaling up of efforts is required. Extrapolating the prevalence of URE in the study area to the entire district yields over 32000 people with URE and a potential 1.1 million people in the country. These numbers have the potential to have far reaching socio-economic implications since URE resulting in distance vision impairment can contribute to a limitation of function and productivity loss. ${ }^{17}$

The association between incomplete schooling and URE may be explained by Liou et al. ${ }^{18}$ who found that education level was a significant predictor of lower likelihood for under-corrected refractive error among people having tertiary level education. They also tend to be more discerning about the quality of their vision and their access to services could be associated with their education and income. ${ }^{18}$ Liou et al. ${ }^{18}$ also found a statistically significant association between occupation and refractive error as found in this study; however, in contrast, the Beaver Dam Eye Study found no association between refractive error and occupation. ${ }^{19}$ Bourne et al. ${ }^{20}$ found that people involved in manual work were more likely to be myopic in comparison to unemployed people; however, the scope of this study did not include the determination of the type of refractive error among subjects.
Although the spectacle coverage for distance correction was estimated at $5.96 \%$ in Uganda, it was much lower than that found in the RARE study conducted in Eritrea (22.2\%; 95\% CI: $16.7 \%-28.5 \%)^{13}$ and higher than that in Tanzania (1.69\%; 95\% CI: $0 \%-3.29 \%) .{ }^{8}$ However, spectacle coverage was consistently higher for presbyopia in both Eritrea (9.9\%; 95\% CI: $7.2 \%-13.4 \%)^{13}$ and Tanzania $(0.42 \%$; 95\% CI: $0-1.26){ }^{8}$ Although $7.8 \%$ of participants with presbyopia wore spectacles, spectacle coverage was calculated at zero percent. Possible explanations include the purchase of ready-made spectacles from vendors or local OCOs without an eye exam, poor knowledge of near vision correction, 'inheriting' a relative's spectacles, or not updating the prescription on a pair of glasses previously prescribed. Health promotion programmes geared towards improving people's knowledge of eye health and refractive services would be an intervention that could improve spectacle usage among presbyopic subjects. The quality of spectacles and the system for spectacle repair and replacement were questioned since two-thirds of those respondents who had previously worn spectacles reported their spectacles were broken or scratched.

The most frequent barriers reported by respondents in the study include affordability of both the service and spectacles and accessibility of the service. Ntsoane and Oduntan $^{21}$ say 'availability, accessibility and affordability of eye care services are important issues in the prevention of visual impairment'.

Since the study was conducted, the data gathered has served as a significant advocacy tool, creating a greater appreciation of the burden of vision impairment in government. This has resulted in greater support for the National Intervention on Uncorrected Refractive Errors. This programme is centred on providing sustainable services through integration of 
refractive services within the health system. The programme has trained OCOs in basic refraction as well as spectacle technicians in cutting and fitting spectacle lenses. This enables the provision of accessible custom-made spectacles at affordable prices. Government's recognition of the burden of vision impairment together with the paucity of a workforce to address the refractive challenges has catalysed the inauguration of the first school of optometry in Makerere University in Uganda with intake having commenced in 2014.

\section{Conclusion}

The RARE has provided helpful insight into the profile of refractive error and presbyopia and barriers to uptake of services in Kamuli district. The prevalence of URE will assist local intervention efforts in planning and implementation of refraction services. Since the study, an OCO has been trained to provide refractive services, thereby improving accessibility of services. However, to serve such a large community an increase in the refractive workforce and the commencement of the optometry programme in Makerere University are needed and should be able to address this concern.

\section{Acknowledgements Competing interests}

The authors declare that they have no financial or personal relationships which may have inappropriately influenced them in writing this article.

\section{Authors' contributions}

N.N. was the principal investigator, implementer of the project and lead author, P.R. was the project leader and coauthor, P.G. was a co-author, V.C., M.W. was a co-author and K.S.N. was co-investigator and senior author.

\section{References}

1. Bourne RRA, Stevens GA, White RA, et al. Causes of vision loss worldwide, 1990-2010 A systematic analysis. Lancet Glob Health. 2013;1(6):e339-e349. http://dx.doi. org/10.1016/S2214-109X(13)70113-X

2. Holden BA, Fricke TR, Ho SM, et al. Global vision impairment due to uncorrected presbyopia. Arch Ophthalmol (Chicago, III 1960). 2008 Dec [cited 2015 Aug 10];126(12):1731-1739. Available from http://www.ncbi.nlm.nih.gov/pubmed/ 19064856
3. Resnikoff S, Pascolini D, Mariotti SP, Pokharel GP. Global magnitude of visual impairment caused by uncorrected refractive errors in 2004. Bull World Health impairment caused by uncorrected refractive errors in 2004. Bull World Health Organ. 2008;86(1):63-70. [cited n.d.].
bulletin/volumes/86/1/07-041210.pdf

4. Jaggernath J, Naidoo K. Uncorrected refractive errors. Indian J Ophthalmol. 2012;60(5):432. http://dx.doi.org/10.4103/0301-4738.100543

5. Enderby P, Pickstone $C$. How many people have communication disorders and why does it matter? Adv Speech-Language Pathol. 2005;7(1):8-13. [cited n.d.] Available from http://www.informaworld.com/10.1080/14417040500055086

6. Marmamula S, Keeffe JE, Rao GN. Uncorrected refractive errors, presbyopia and spectacle coverage: Results from a rapid assessment of refractive error survey. Ophthalmic Epidemiol. 2009;16(5):269-274. http://dx.doi.org/10.1080/ 09286580903144720

7. Marmamula S, Keeffe JE, Raman U, Rao GN. Population-based cross-sectional study of barriers to utilisation of refraction services in South India: Rapid Assessment of Refractive Errors (RARE) Study. BMJ Open. 2011 Jan 1;1(1):e000172. http://dx.doi.org/10.1136/bmjopen-2011-000172

8. Mashayo ER, Chan VF, Ramson P, Chinanayi F, Naidoo KS. Prevalence of refractive error, presbyopia and spectacle coverage in Kahama District, Tanzania: A rapid assessment of refractive error. Clin Exp Optom. 2015 [cited 2015 Jun 10];98(1): 58-64. Available from http://www.ncbi.nlm.nih.gov/pubmed/25271145

9. Mbulaiteye SM, Reeves BC, Mulwanyi F, Whitworth JAG, Johnson G. Incidence of visual loss in rural southwest Uganda. Br J Ophthalmol. 2003;87(7):829-833. http://dx.doi.org/10.1136/bjo.87.7.829

10. Roome E, Raven J, Martineau T. Human resource management in post-conflict health systems: review of research and knowledge gaps. Confl Health. 2014 Jan;8(1):18. http://dx.doi.org/10.1186/1752-1505-8-18

11. Tornberg $\mathrm{H}$. Ethnic fragmentation and political instability in post-colonial Uganda understanding the contribution of colonial rule to the plights. Lund: Lunds Universitet; 2012.

12. Kamali A, Whitworth JA, Ruberantwari A, Mulwanyi F, Acakara M, Dolin P, et al. Causes and prevalence of non-vision impairing ocular conditions among a rura adult population in SW Uganda. Ophthalmic Epidemiol. 1999;6(1):41-48. http://dx.doi.org/10.1076/opep.6.1.41.1572

13. Chan VF, Mebrahtu G, Ramson P, Wepo M, Naidoo KS. Prevalence of refractive error and spectacle coverage in Zoba Ma'ekel Eritrea: A rapid assessment of refractive error. Ophthalmic Epidemiol. 2013 Jun [cited 2015 Sep 11];20(3): 131-137. Available from http://www.ncbi.nlm.nih.gov/pubmed/23713915

14. Uganda Bureau of Statistics. Population Size and Distribution. The 2002 Uganda Population and Housing Census. 2006 [cited 2015 Jun 06]. p. 46. Available from http://www.ubos.org/onlinefiles/uploads/ubos/pdf documents/2002 CensusPopnSizeGrowthAnalyticalReport.pdf

15. Govender P, Ramson P, Visser L, Naidoo KS. Rapid assessment of avoidable blindness in the northern eThekwini district of KwaZulu-Natal Province, South Africa. Afr Vision Eye Health. 2015 [cited 2016 Feb 10]. Available from http:// saoptometrist.co.za/index.php/aveh/article/view/15

16. Uganda Bureau of Statistics. Where are the poor? Mapping Patterns of Well-Being in Uganda: 1992 \& 1999. 2004 [cited 2015 Jun 06]. Available from http://www. ubos.org/onlinefiles/uploads/ubos/pdf documents/Uganda Poverty Atlas optimized.pdf

17. Smith TST, Frick KD, Holden BA, Fricke TR, Naidoo KS. Potential lost productivity resulting from the global burden of uncorrected refractive error. Bull World Health Organ. 2009;87(6):431-437. http://dx.doi.org/10.2471/BLT.08.055673

18. Liou HL, McCarty CA, Jin CL, Taylor HR. Prevalence and predictors of undercorrected refractive errors in the Victorian population. Am J Ophthalmol. 1999 May;127(5):590-596. http://dx.doi.org/10.1016/S0002-9394(98)00449-8

19. Wang $Q$, Klein BEK, Klein R, Moss SE. Refractive status in the Beaver Dam Eye Study. Investig Ophthalmol Vis Sci. 1994;35(13):4344-4347.

20. Bourne RRA, Dineen BP, Ali SM, Noorul Huq DM, Johnson GJ. Prevalence of refractive error in Bangladeshi adults: Results of the National Blindness and Low Vision Survey of Bangladesh. Ophthalmology. 2004 Jun;111(6):1150-1160. http://dx.doi. org/10.1016/j.ophtha.2003.09.046

21. Ntsoane $M$, Oduntan $\mathrm{O}$. A review of factors influencing the utilization of eye care services. S Afr Optom. 2010;69(4):182-192. 